JURNAL BASICEDU

Research \& Learning in Elementary Education

https://jbasic.org/index.php/basicedu

\title{
PENINGKATAN HASIL BELAJAR SISWA DENGAN MODEL PROBLEM BASED LEARNING DI SEKOLAH DASAR
}

\author{
Alfia Rahmi ${ }^{1}$ \\ Universitas Negeri Padang, Sumatera Barat, Indonesia ${ }^{1}$ \\ Email: Alfiarahmi66@gmail.com ${ }^{1}$,
}

\begin{abstract}
Abstrak
Penelitian ini dilatar belakangi oleh pembelajaran PKn yang selama ini masih berpusat kepada guru sehingga pembelajaran PKn berlangsung membosankan.Tujuan penelitian ini adalah untuk mendeskripsikan peningkatkan hasil belajar PKn dengan menggunakan model Problem Based learning (PBL). Hasil penelitian dari pengamatan RPP pada siklus I rata-rata 83,9\% meningkat pada siklus II 92,9\% sedangkan aspek guru pada siklus I rata-rata 78,5\% meningkat pada siklus II menjadi 92,8\% dan aspek siswa pada siklus I rata-rata 78,5\% meningkat pada siklus II menjadi 89,2\%. Penilaian hasil belajar siswa siklus I diperoleh hasil 76,28 dan pada siklus II diperoleh hasil 89,5. Hal ini menunjukkan hasil belajar PKn siswa kelas IV SDN 10 Sungai Sapih Kota Padang meningkat dengan menerapkan model pembelajaran Problem Based Learning $(P B L)$.

Kata Kunci : Pembelajaran Model Problem Based Learning di Sekolah Dasar
\end{abstract}

\begin{abstract}
Abstrack
This research is motivated by Civics learning which is still centered on the teacher so that Civics learning takes place is boring. The purpose of this study is to describe the improvement of Civics learning outcomes by using the Problem Based Learning (PBL) model. The results of the observation of RPP in the first cycle an average of $83.9 \%$ increased in the second cycle $92.9 \%$ while the aspect of the teacher in the first cycle an average of $78.5 \%$ increased in the second cycle to $92.8 \%$ and aspects of students in the cycle I an average of $78.5 \%$ increased in the second cycle to $89.2 \%$. Assessment of student learning outcomes in the first cycle results obtained 76.28 and in the second cycle results obtained 89.5. This shows the learning outcomes of PKn students in grade IV SDN 10 Sungai Sapih, Padang City increased by applying the Problem Based Learning (PBL) learning model.
\end{abstract}

Keywords: Learning Problem Based Learning Model in Elementary School

@ Jurnal Basicedu Prodi PGSD FIP UPTT 2019

$\triangle$ Corresponding author :

Address :

Email : alfiarahmi766@gmail.co.id

ISSN 2580-3735 (Media Cetak)

Phone

ISSN 2580-1147 (Media Online) 


\section{PENDAHULUAN}

Berdasarkan hasil observasi dan wawancara yang dilakukan peneliti pada tanggal 18 Oktober, 19 Oktober, dan 25 Oktober 2016 di kelas IV SD Negeri 10 Sungai Sapih Padang ditemukan beberapa permasalahan dari segi perencanaan dan pelaksanaanpembelajaran PKn. Pertama, dari segi perencanaan yaitu 1) tujuan pembelajaran pada RPP tidak mengandung ABCD (Audience, Behaviors, Condition, Degree 2) pada RPP yang dirancang tidak mencantumkan lembar penilaian kognitif, afektif dan psikomotor.Kedua, dari segi pelaksanaan yaitu1) guru kurang mengaitkan materi dengan kehidupan nyata siswa, 2) guru kurang menggali pengetahuan siswa dengan mengajukan pertanyaan yang berhubungan dengan materi pelajaran yang akan diajarkan, 3) guru kurang melakukan diskusi kelompok dalam proses pembelajaran PKn di SD, 4) guru kurang memberikan waktu kepada siswa untuk melatih mengeluarkan pendapat.

Untuk mengatasi kondisi di atas perlu diadakan pembaharuan pada model mengajar guru. Guru sebaiknya memakai model pembelajaran yang mampu menuntut siswa untuk berpikir kritis dalam memecahkan masalah, aktif bekerja sama di dalam kelompok, setiap siswa bebas mengemukakan idenya dengan teman yang lain dan mengaitkan pengalaman kehidupan nyata siswa dengan materi tersebut. Menurut Duch (dalam Ryanto 2010:285) "Problem Based Learning (PBL) adalah suatu model pengajaran yang menghadapkan peserta didik pada tantangan belajar untuk siswa".

Berdasarkan latar belakang masalah yang dikemukakan di atas maka yang menjadi permasalahan secara umum adalah "Bagaimanakah Peningkatan Hasil Belajar Siswa dalam Pembelajaran Pendidikan Kewarganegaraan (Pkn) dengan Menggunakan Model Pembelajaran
Problem Based Learning (PBL) di Kelas IV SD

Negeri 10 Sungai Sapih Padang".Rumusan masalah secara khusus yaituBagaimanakah rencana pelaksanaan pembelajaran Pkn untuk meningkatkan hasil belajar siswa menggunakan model pembelajaran Problem Based Learning (PBL) di Kelas IV SD Negeri 10 Sungai Sapih Padang, mendeskripsikan bagaimana pelaksanaan, dan penerapan model Problem Based Learning (PBL) untuk meningkatkan hasil belajar siswa pada pembelajaran PKn.

\section{METODE}

Jenis penelitian yang dilaksanakan adalah Penelitian Tindakan Kelas (PTK). Penelitian tindakan kelas adalah penelitian yang dilaksanakan didalam kelas. Menurut Hamzah (2012:41) "Penelitian Tindakan Kelas adalah penelitian yang di lakukan oleh guru di dalam kelasnya sendiri melalui refleksi diri, dengan tujuan untuk memperbaiki kinerjanya sebagai guru, sehingga proses pembelajaran dapat berjalan dengan baik, dan hasil belajar siswa meningkat".

Penelitian ini dilaksanakan dengan menggunakan model siklus dengan empat tahapan.Empat tahapan yang dilakukan dalam penelitian tindakan kelas sesuai dengan pendapat Kemmis dan M.C Taggart (dalam Uno, 2011:87) yaitu: (a) perencanaan, (b) pelaksanaan,(c) pengamatan, dan $(\mathrm{d})$ refleksi.

Penelitian ini dilaksanakan pada semester II Januari-Juni tahun ajaran 2016/2017. Penilitian ini dilaksanakan dalam 2 siklus dengan siklus 1 dua kali pertemuan dan siklus 2 satu kali pertemuan. Siklus I pertemuan pertama telah dilaksanakan pada hari Kamis tanggal 26 April2017. Siklus I pertemuan kedua pada hari Kamis tanggal 4 Mei2017. Siklus II pada hari Kamis tanggal 9 Mei 2017. Jumlah siswa yaitu 33 orang siswa.

Penelitian ini dikumpulkan dengan menggunakan lembar observasi dan tes. Data 
tersebut berkaitan dengan: (1) rencana pelaksanaan pembelajaran yang dilakukan guru sebelum mengajar, (2) pengamatan terhadap aktivitas guru dan aktivitas siswa. Sedangkan sumber data penelitian ini adalah guru dan siswa kelas IV SDN 10 Sungai Sapih Kota Padang.

Pendekatan yang peneliti gunakan dalam penelitian ini menggunakan pendekatan kualitatif dan kuantitatif. Pendekatan kualitatif diuraikan dengan mendeskripsikan penelitian dengan katakata terhadap apa yang dialami oleh sebjek penelitian sedangkan pendekatan kuantitatif dengan menggunakan angka-angka dalam mendeskripsikan subjek penelitian. Penelitian ini menguraikan penerapan model Problem Based Learning (PBL)untuk meningkatkan hasil belajar siswa pada pembelajaran PKn dikelas IV SDN 10 Sungai Sapih Kota Padang .Untuk perhitungan persentase dilakukan dengan menggunakan pendekatan kuantitatif yang dikemukakan Ngalim (2012:102): menggunakan rumus sebagai berikut : $\mathrm{NP}=\frac{R}{S M} \times 100 \%$

Keterangan:

$\mathrm{NP}=$ Nilai Persen yang diharapkan

$\mathrm{R}=$ Skor yang diperoleh

$\mathbf{M}=$ Skor Maksimal ideal dari tes yang bersangkutan

$100=$ Bilangan tetap

\section{HASIL DAN PEMBAHASAN}

Pada siklus I penelitian dilakukan $2 \mathrm{x}$ pertemuan. Penelitian dilakukan sesuai dengan alur yang telah dibuat, yaitu : 1) perencanaan, 2) pelaksanaan, 3) pengamatan, dan 4) refleksi.
Tabel 1. Siklus I Pertemuan I

\begin{tabular}{|c|c|c|c|c|c|c|}
\hline No & Nama & Nilai & KKM & Ketuntasan & Tuntas & $\begin{array}{l}\text { Tidak } \\
\text { Tuntas }\end{array}$ \\
\hline 1 & ADP & 70 & 80 & $70 \%$ & - & $\sqrt{ }$ \\
\hline 2 & AO & 75 & 80 & $75 \%$ & - & $\sqrt{ }$ \\
\hline 3 & APK & 100 & 80 & $100 \%$ & $\sqrt{ }$ & $\sqrt{ }$ \\
\hline 4 & AHR & 90 & 80 & $90 \%$ & $\sqrt{ }$ & $\sqrt{ }$ \\
\hline 5 & AA & 75 & 80 & $75 \%$ & - & $\sqrt{ }$ \\
\hline 6 & $\mathbf{A A}$ & 95 & 80 & $95 \%$ & $\sqrt{ }$ & - \\
\hline 7 & $\mathrm{CU}$ & 85 & 80 & $85 \%$ & $\sqrt{ }$ & - \\
\hline 8 & DL & 40 & 80 & $40 \%$ & - & $\sqrt{ }$ \\
\hline 9 & DAF & 90 & 80 & $90 \%$ & $\sqrt{ }$ & - \\
\hline 10 & DDA & 85 & 80 & $85 \%$ & $\sqrt{ }$ & - \\
\hline 11 & FAR & 50 & 80 & $50 \%$ & - & $\sqrt{ }$ \\
\hline 12 & HPP & 85 & 80 & $85 \%$ & $\sqrt{ }$ & - \\
\hline 13 & HSM & 75 & 80 & $75 \%$ & - & $\sqrt{ }$ \\
\hline 14 & IMR & 50 & 80 & $50 \%$ & - & $\sqrt{ }$ \\
\hline 15 & IG & 90 & 80 & $90 \%$ & $\sqrt{ }$ & - \\
\hline 16 & MDA & 60 & 80 & $60 \%$ & - & $\sqrt{ }$ \\
\hline 17 & MFG & 50 & 80 & $50 \%$ & - & $\sqrt{ }$ \\
\hline 18 & MR & 55 & 80 & $55 \%$ & - & $\sqrt{ }$ \\
\hline 19 & MYQ & 90 & 80 & $90 \%$ & $\sqrt{ }$ & - \\
\hline 20 & MZA & 75 & 80 & $75 \%$ & - & $\sqrt{ }$ \\
\hline 21 & MDAP & 75 & 80 & $75 \%$ & - & $\sqrt{ }$ \\
\hline 22 & MF & 75 & 80 & $75 \%$ & - & $\sqrt{ }$ \\
\hline 23 & MMG & 65 & 80 & $65 \%$ & - & $\sqrt{ }$ \\
\hline 24 & NS & 50 & 80 & $50 \%$ & - & $\sqrt{ }$ \\
\hline 25 & ND & 85 & 80 & $85 \%$ & $\sqrt{ }$ & - \\
\hline 26 & PM & 60 & 80 & $60 \%$ & - & $\sqrt{ }$ \\
\hline 27 & $\begin{array}{l}\text { PFT } \\
\end{array}$ & 90 & 80 & $90 \%$ & $\sqrt{ }$ & - \\
\hline 28 & PSN & 50 & 80 & $50 \%$ & - & $\sqrt{ }$ \\
\hline 29 & $\mathbf{Q A}$ & 70 & 80 & $70 \%$ & - & $\sqrt{ }$ \\
\hline 30 & RAP & 50 & 80 & $50 \%$ & - & $\sqrt{ }$ \\
\hline 31 & RNI & 90 & 80 & $90 \%$ & $\sqrt{ }$ & - \\
\hline 32 & TPR & 90 & 80 & $90 \%$ & $\sqrt{ }$ & - \\
\hline 33 & $\begin{array}{l}\text { ZNP } \\
\end{array}$ & 90 & 80 & $90 \%$ & $\sqrt{ }$ & - \\
\hline \multicolumn{2}{|c|}{ Jumlah } & 2625 & & & 14 & 19 \\
\hline \multicolumn{2}{|c|}{ Rata-rata } & 75.00 & & $75.00 \%$ & $42 \%$ & $58 \%$ \\
\hline
\end{tabular}

Tabel 2. Siklus I pertemuan II

\begin{tabular}{|c|c|c|c|c|c|c|}
\hline No & Nama & Nilai & KKM & Ketuntasan & Tuntas & $\begin{array}{l}\text { Tidak } \\
\text { Tuntas }\end{array}$ \\
\hline 1 & ADP & 75 & 80 & $75 \%$ & - & $\sqrt{ }$ \\
\hline 2 & AO & 80 & 80 & $80 \%$ & $\sqrt{ }$ & - \\
\hline 3 & APK & 100 & 80 & $100 \%$ & $\sqrt{ }$ & - \\
\hline 4 & AHR & 90 & 80 & $90 \%$ & $\sqrt{ }$ & - \\
\hline 5 & AA & 80 & 80 & $80 \%$ & $\sqrt{ }$ & - \\
\hline 6 & $\mathbf{A A}$ & 95 & 80 & $95 \%$ & $\sqrt{ }$ & - \\
\hline 7 & $\mathrm{CU}$ & 90 & 80 & $90 \%$ & $\sqrt{ }$ & - \\
\hline 8 & DL & 75 & 80 & $75 \%$ & - & $\sqrt{ }$ \\
\hline 9 & DAF & 90 & 80 & $90 \%$ & $\sqrt{ }$ & - \\
\hline 10 & DDA & 85 & 80 & $85 \%$ & $\sqrt{ }$ & - \\
\hline 11 & FAR & 70 & 80 & $70 \%$ & - & $\sqrt{ }$ \\
\hline 12 & HPP & 90 & 80 & $90 \%$ & $\sqrt{ }$ & - \\
\hline 13 & HSM & 80 & 80 & $80 \%$ & $\sqrt{ }$ & - \\
\hline 14 & IMR & 75 & 80 & $75 \%$ & - & $\sqrt{ }$ \\
\hline 15 & IG & 85 & 80 & $85 \%$ & $\sqrt{ }$ & - \\
\hline 16 & MDA & 70 & 80 & $70 \%$ & - & $\sqrt{ }$ \\
\hline 17 & MFG & 75 & 80 & $75 \%$ & - & $\sqrt{ }$ \\
\hline 18 & MR & 80 & 80 & $80 \%$ & $\sqrt{ }$ & - \\
\hline 19 & MYQ & 90 & 80 & $90 \%$ & $\sqrt{ }$ & - \\
\hline 20 & MZA & 85 & 80 & $85 \%$ & $\sqrt{ }$ & - \\
\hline 21 & MDAP & 85 & 80 & $85 \%$ & $\sqrt{ }$ & - \\
\hline 22 & MF & 80 & 80 & $80 \%$ & $\sqrt{ }$ & - \\
\hline 23 & MMG & 75 & 80 & $75 \%$ & - & $\sqrt{ }$ \\
\hline 24 & NS & 80 & 80 & $80 \%$ & $\sqrt{ }$ & - \\
\hline 25 & ND & 85 & 80 & $85 \%$ & $\sqrt{ }$ & - \\
\hline 26 & PM & 80 & 80 & $80 \%$ & $\sqrt{ }$ & - \\
\hline 27 & PFT & 90 & 80 & $90 \%$ & $\sqrt{ }$ & - \\
\hline 28 & PSN & 85 & 80 & $85 \%$ & $\sqrt{ }$ & - \\
\hline 29 & QA & 80 & 80 & $80 \%$ & $\sqrt{ }$ & - \\
\hline 30 & RAP & 75 & 80 & $75 \%$ & - & $\sqrt{ }$ \\
\hline 31 & RNI & 90 & 80 & $90 \%$ & $\sqrt{ }$ & - \\
\hline 32 & TPR & 95 & 80 & $95 \%$ & $\sqrt{ }$ & - \\
\hline 33 & ZNP & 100 & 80 & $100 \%$ & $\sqrt{ }$ & - \\
\hline \multicolumn{2}{|c|}{ Jumlah } & 2760 & & & 25 & 8 \\
\hline \multicolumn{2}{|c|}{ Rata-rata } & 83.64 & & $83.64 \%$ & $75 \%$ & $25 \%$ \\
\hline
\end{tabular}


Dari refleksi pada siklus I, disimpulkan bahwa tujuan pembelajaran yang diharapkan pada siklus I belum tercapai dengan baik. Dengan demikian, penerapan Model Problem Based Learning (PBL) peneliti lanjutkan pada siklus II dengan memperhatikan kendalakendala yang ditemui pada siklus I. Kendalakendala yang ditemui pada siklus I akan diperbaiki pada siklus II

\section{Siklus II}

Pada siklus II penelitian dilakukan $1 \mathrm{x}$ pertemuan yang dilaksanakan pada Hari Kamis tanggal 9 Mei 2017. Penelitian dilakukan sesuai dengan alur yang telah dibuat, yaitu : 1) perencanaan, 2) pelaksanaan, 3) pengamatan, dan 4) refleksi. Hal tersebut dapat dideskripsikan sebagai berikut :

Tabel 3. Siklus II

\begin{tabular}{|c|c|c|c|c|c|c|}
\hline No & Nama & Nilai & KKM & Ketuntasan & Tuntas & $\begin{array}{l}\text { Tidak } \\
\text { Tuntas }\end{array}$ \\
\hline 1 & ADP & 80 & 80 & $80 \%$ & $\sqrt{ }$ & - \\
\hline 2 & $\mathrm{AO}$ & 85 & 80 & $85 \%$ & $\sqrt{ }$ & - \\
\hline 3 & APK & 100 & 80 & $100 \%$ & $\sqrt{ }$ & - \\
\hline 4 & AHR & 90 & 80 & $90 \%$ & $\sqrt{ }$ & - \\
\hline 5 & AA & 90 & 80 & $90 \%$ & $\sqrt{ }$ & - \\
\hline 6 & AA & 100 & 80 & $100 \%$ & $\sqrt{ }$ & - \\
\hline 7 & $\mathrm{CU}$ & 90 & 80 & $90 \%$ & $\sqrt{ }$ & - \\
\hline 8 & DL & 75 & 80 & $75 \%$ & - & $\sqrt{ }$ \\
\hline 9 & DAF & 90 & 80 & $90 \%$ & $\sqrt{ }$ & - \\
\hline 10 & DDA & 85 & 80 & $85 \%$ & $\sqrt{ }$ & - \\
\hline 11 & FAR & 85 & 80 & $85 \%$ & $\sqrt{1}$ & 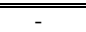 \\
\hline 12 & HPP & 90 & 80 & $90 \%$ & $\sqrt{ }$ & - \\
\hline 13 & HSM & 85 & 80 & $85 \%$ & $\sqrt{ }$ & - \\
\hline 14 & IMR & 90 & 80 & $90 \%$ & $\sqrt{ }$ & - \\
\hline 15 & IG & 85 & 80 & $85 \%$ & $\sqrt{ }$ & - \\
\hline 16 & MDA & 85 & 80 & $85 \%$ & $\sqrt{ }$ & - \\
\hline 17 & MFG & 75 & 80 & $75 \%$ & - & $\sqrt{ }$ \\
\hline 18 & MR & 90 & 80 & $90 \%$ & $\sqrt{ }$ & - \\
\hline 19 & MYQ & 100 & 80 & $100 \%$ & $\sqrt{ }$ & - \\
\hline 20 & MZA & 85 & 80 & $85 \%$ & $\sqrt{ }$ & - \\
\hline 21 & MDAP & 85 & 80 & $85 \%$ & $\sqrt{ }$ & - \\
\hline 22 & MF & 85 & 80 & $85 \%$ & $\sqrt{ }$ & - \\
\hline 23 & MMG & 85 & 80 & $85 \%$ & $\sqrt{ }$ & - \\
\hline 24 & NS & 85 & 80 & $85 \%$ & $\sqrt{ }$ & - \\
\hline 25 & ND & 90 & 80 & $90 \%$ & $\sqrt{ }$ & - \\
\hline 26 & PM & 85 & 80 & $85 \%$ & $\sqrt{ }$ & - \\
\hline 27 & PFT & 95 & 80 & $95 \%$ & $\sqrt{ }$ & - \\
\hline 28 & PSN & 95 & 80 & $95 \%$ & $\sqrt{ }$ & - \\
\hline 29 & QA & 85 & 80 & $85 \%$ & $\sqrt{ }$ & - \\
\hline 30 & RAP & 80 & 80 & $80 \%$ & $\sqrt{ }$ & - \\
\hline 31 & RNI & 100 & 80 & $100 \%$ & $\sqrt{ }$ & - \\
\hline 32 & TPR & 100 & 80 & $100 \%$ & $\sqrt{ }$ & - \\
\hline 33 & ZNP & 100 & 80 & $100 \%$ & $\sqrt{ }$ & - \\
\hline \multicolumn{2}{|c|}{ Jumlah } & 2925 & & & 31 & 2 \\
\hline \multicolumn{2}{|c|}{ Rata-rata } & 89.05 & & $89.5 \%$ & $94 \%$ & $6 \%$ \\
\hline
\end{tabular}

\section{PEMBAHASAN}

Penelitian ini telah membuktikan bahwa penggunaan $\mathrm{PBL}$ dalam pembelajaran dapat meningkatkan hasil belajar siswa serta dapat mengembangkan kemampuan berfikir siswa secara kritis. Dengan hal ini berarti PBL dapat digunakan oleh guru sebagai suatu model pembelajaran yang baik untuk diterapkan dalam proses pembelajaran sehingga dapat mencapai tujuan yang diinginkan serta dapat menciptakan suasana belajar yang menyenangkan bagi siswa. Selain itu Amir (2010:1) menjelaskan bahwa pembelajaran efektif berarti "pembelajaran yang mencapai tujuan, siswa belajar meraih target sesuai dengan kriteria target pada perencanaan, siswa dapat menyerap materi pelajaran dan mempraktekkannya menggunakan waktu yang sesingkat-singkatnya dengan hasil setinggi-tingginya.

Berdasarkan analisis penelitian pada siklus I pertemuan I,II dan Siklus II, penerapan PBL telah terlaksana sesuai dengan yang diharapkan. Melihat hasil yang diperoleh pada siklus II, maka pelaksanaan siklus II telah terlaksana dengan baik sejalan dengan pendapat Kunandar (2008:428) yaitu, ketuntasan hasil belajar yang ideal adalah $75 \%$, dan ketuntasan hasil belajar siswa pada siklus II ini telah mencapai lebih dari $75 \%$ jadi dapat disimpulkan peneliti telah berhasil menerapkan model PBL pada pembelajaran PKn di kelas IV SDN 10 Sungai Sapih Kota Padang dan telah dapat meningkatkan hasil belajar siswa sehingga tidak dilanjutkan dengan siklus berikutnya.

\section{SIMPULAN}

Berdasarkan data hasil penelitian dan pembahasan tentang peningkatan hasil belajar siswa dalam pembelajaran PKn dengan menggunakan model PBL, maka dapat diambil simpulan sebagai berikut:Berdasarkan hasil 
pengamatan pada penilaian RPP terlihat bahwa pada siklus I rata-rata hasil belajar yang diperoleh yaitu dengan skor 24. Pada siklus I terlihat RPP yang dibuat belum maksimal, sehingga hasil belajar yang diperoleh siswa pun belum sesuai dengan apa yang diharapkan. Kendala-kendala yang ditemui pada RPP siklus I diperbaiki pada siklus II, sehingga pada siklus II penilaian RPP memperoleh rata-rata persentase $92,9 \%$ dengan kualifikasi sangat baik (SB), jadi terlihat bahwa adanya peningkatan pada aspek RPP.

Hal ini dikarenakan berbagai kendala diatas sudah dapat diatasi dengan baik dan ratarata deskriptor yang muncul juga meningkat, sehingga terjadi peningkatan pada siklus ke II. Pelaksanaan pembelajaran PKn dengan PBL terdiri dari kegiatan awal pembelajaran, kegiatan inti pembelajaran, dan kegiatan akhir pembelajaran. Pelaksanaan pembelajaran PKn dengan mnggunakan 4 langkah PBL yaitu: (1) memulai masalah autentik, (2) pemecahan masalah, (3) presentase hasil pemecahan, (4) simpulan atas pemecahan.

Hasil pengamatan dari pelaksanaan pembelajaran dengan model PBL pada siklus I menunjukkanbahwa pelaksanaan pembelajaran dari aspek guru dan aspek siswa masih belum maksimal, persentase yang diperoleh pada aspek guru adalah 83,3\% dan aspek siswa 80,5\%. Pada siklus II pada aspek guru mencapai $97,2 \%$ dan aspek siswa mencapai $89,5 \%$. Dari hal ini terlihat bahwa ada peningkatan pada tahap pelasanaan baik itu dari aspek guru maupun siswa.Hasil belajar siswa dengan menggunakan model PBL dalam pembelajaran PKn di kelas IV SDN 10 Sungai Sapih Kota Padang, dapat meningkatkan hasil belajar siswa.Hal ini dapat dilihat dari rekapitulasi penilaian hasil belajar siswa. Rekapitulasi hasil penilaian proses pada siklus I juga sudah mengalami peningkatan pada siklus II dimana siswa sudah banyak memperoleh nilai diatas ketuntasan yang ditetapkan.

\section{DAFTAR PUSTAKA}

Kunandar.2011. Guru Profesional Implementasi Kurikulum Tingkat Satuan Pendidikan (KTSP) dan Sukses dalam Sertifikasi Guru.Jakarta: Rajawali Pers.

Muslich, Manur.2010. Melaksanakan PTK itu mudah. Malang: Bumi Aksara.

Purwanto, Ngalim. 2006. Primsip-prinsip dan Teknik Evaluasi Pengajaran. Bandung: PT Remaja Rosdakarya.

Riyanto, Yatim. 2010. Paradigma Baru Pembelajaran. Jakarta: Kencana

Sanjaya, Wina. 2008. Perencanaan dan Desain Sistem Pembelajaran. Jakarta: Kencana Predanada Media Grup

Trianto.2011. Mendesain Model Pembelajaran Inovatif-Progresif. Jakarta: Kencana

Uno, Hamzah B. 2011. Model Pembelajaran: Menciptakan Proses Belajar Aktif Dan Efektif. Jakarta: Bumi Aksara. 